\title{
Synthesis of 2,3-Dihydro-6-methyl-2-thiopyrimidin-4(1H)-one (6-Methylthiouracil) Derivatives and Their Reactions
}

\author{
Mohammad Barmaki, ${ }^{1}$ Gulgaz Valiyeva, ${ }^{2}$ Abel A. Maharramovm, ${ }^{2}$ and Mirze M. Allaverdiyev ${ }^{2}$ \\ ${ }^{1}$ Faculty of Chemistry, North Tehran Branch, Islamic Azad University, Tehran, Iran \\ ${ }^{2}$ Department of Chemistry, Baku State University, Baku, Azerbaijan
}

Correspondence should be addressed to Mohammad Barmaki; m_barmaki@iau-tnb.ac.ir

Received 21 August 2011; Accepted 9 November 2011

Academic Editor: N. A. Mohamed Farook

Copyright (c) 2013 Mohammad Barmaki et al. This is an open access article distributed under the Creative Commons Attribution License, which permits unrestricted use, distribution, and reproduction in any medium, provided the original work is properly cited.

\begin{abstract}
The synthesis and characterization of 2,3-dihydro-6-methyl-2-thioxopyrimidin-(1H)-one (I) and some of its derivatives has been performed in our lab. Ring-closing cyclization, as a result of the condensation of ethyl-3-oxobutanoate with thiourea in $\mathrm{KOH}$ in an ethanol medium produced 2,3-dihydro-6-methy -2-thioxopyrimidin-(1H)-one (I). The reaction of compound (I) with 2chloroacetic acid in an alkaline $\mathrm{KOH}$ solution produced the carboxylate derivative, 2-(2,6-dihydro-4-methyl-6-oxopyrimidin-2-ylthio)ethanoic acid (II). The reaction of the resulted derivative of carboxylate (II) with the salt of copper sulphate, produced a new copper salt (III). A substitution reaction between synthesized compound (I) and 2-chloroethanol in an aqueous solution of $\mathrm{KOH}$, created 2-(2-hydroxyethylthio)-6-methylpyrimidin-4(3H)-one (IV). The reaction of compound (I) with 2-(chloromethyl)oxirane in the presence of an aqueous solution of $\mathrm{KOH}$, resulted yielded 2-(3-chloro-2-hydroxy-propylthio)-6-methylpyrimidin-4(3H)-one (V). Sodium mercaptide compound (VI), was produced by the reaction of (I) with $\mathrm{NaOH}$ and then the sodium salt of 2,3-dihydro6-methyl-2-thioxopyrimidin-(1H)-one (VI) was reacted with 2-(chloromethyl)oxirane to result in 2-((oxiran-2-yl) methyl-thio)6-methyl-pyrimidin-4(3H)-one (VII). Different acylation reagents (acetyl chloride, benzoyl chloride) were reacted with compound (I), in dimethylformamide, acylation happens on sulfur and furnished S-acylified derivatives of (VIII-IX). All the synthesized and obtained products were confirmed by IR, ${ }^{1} \mathrm{H}$, and ${ }^{13} \mathrm{C}$ NMR and elemental analysis.
\end{abstract}

\section{Introduction}

Among hexagonal heterocycles, pyrimidine has extensive and special applications in chemistry and biochemistry. The structure of pyrimidine is used in medical compounds. For example, Vitamin B1 or thiamin has the pyrimidine ring in its structure [1]. Synthesized derivatives of barbituric acid and sleep-inducing medications like Luminal and veronal (Barbitone) are also from this category of compounds.

Moreover pyrimidines generally have attracted much interest for their widespread potential in biological activities and medicinal applications, thus their chemistry has been investigated extensively $[2,3]$. In particular, various analogues of pyrimidine-thiones possess effective antibacterial, antifungal, antiviral, anti-AIDS, insecticidal and medicinal applications $[4,5]$.
Furthermore many condensed heterocyclic systems, especially when they are linked to a pyrimidine ring, play an important role as analgesic, antihypertensive [6], antipyretic and anti-inflammatory drugs $[7,8]$. They also find use as pesticides, herbicides, and plant growth regulators [9]. Among pyrimidines derivatives, uracil is one of the important bases which can be found in nucleic acids and has different efficient derivatives with broad effects.

The importance of uracil and its annealed derivatives is well recognized by synthetic [10], as well as biological [11], chemists. For example, pyrazolo[3,4-d]pyrimidines constitute a class of naturally occurring fused uracils that possess diverse biological activities [12].

5 -Flourouracil itself is used in the biosynthesis of the molecular structure of RNA [13]. 5-Bromouracil alternates' hereditary information carries the chemical properties of 
mutants at high speed and in mutant parts affect alkaline changes of amines.

According to scientific studies [14], thiouracil derivatives are tranquilizers of the nervous system; they also play protective roles in human immunity against viruses. Other uracil derivatives such as 5-oximethyl-4-methyluracil (Pentoil) and 4-methyluracil (Metoil) are quite effective against colds.

Pentoil, metoil, and uracil play very important roles in anemia, nucleic acid synthesis, and biosynthesis of blood proteins. Derivatives of thiouracil have extended applications in the treatment of nervous disorders. These compounds can also be used for the treatment of Alzheimer's disease, Parkinson's disease, migraines, depression and amnesia.

Nowadays, uracil derivatives are successfully applied in immunotherapy and as an implement to show the stability of the properties of the cell membrane [15]. Uracil derivatives are also useful in the biosynthesis of xanthines [16].

Herein, some of the synthesized derivatives of compounds, 6-amino-4-hydroxy-2-mercaptopyrimidine [17], synthesis of uracil derivatives and some of their reactions have been reported alongside our previous investigations [18].

The purpose of this paper in the context of organic chemistry is the "synthesis, cyclization and reactions of given reactants", which plays an important role in this branch of chemistry. Moreover, uracil derivatives have important usages in medical sciences, as mentioned above. It seems selfevident that these synthesized compounds have also been investigated from a biological point of view and are being studied by biologists and will be presented in a separate paper.

The most available routes for the synthesis of 1-aryl- or 1-heteroaryl-5-substituted uracil derivatives involve condensation reactions [19]. In an effort to increase the molecular structures, that is, in the synthesis of uracil and its derivatives, we have developed a novel synthesis method by applying Diels-Alder reactions [20] and an efficient synthesis by using catalytic material [21].

\section{Experimental}

${ }^{1} \mathrm{H}$ and ${ }^{13} \mathrm{C}$ NMR spectra of all synthesized compounds were obtained using a Bruker ABM-300 spectrometer. Chemical shifts $(\delta)$ are given in ppm using TMS as an internal reference. IR spectra were recorded on Spekord 75-IR. Thin Layer Chromatography (TLC) was performed on silica gel plates. Silufol UV-254 nm in chloroform-methanol $(20: 1 \mathrm{~V} / \mathrm{V})$ and chloroform-methanol $(9: 1 \mathrm{~V} / \mathrm{V})$ were used as solvent systems. Plates were visualized with iodine vapor under UV light.

2.1. 2,3-Dihydro-6-methyl-2-thioxopyrimidin-(1H)-one (I). $\mathrm{KOH}$ along with ethanol are mixed with ethylacetoacetate and thiourea in a three-necked round-bottomed flask with thermometer and a back flow condenser on the magnetic stirrer. The required amount of each compound is as follows: ethyl-3-oxobutanoate $28.0 \mathrm{~g}(0.2 \mathrm{~mL})$, thiourea $15.2 \mathrm{~g}(0.2 \mathrm{~mL}), \mathrm{KOH} 9.0 \mathrm{~g}(0.16 \mathrm{~mL})$ and ethanol $15.0 \mathrm{~mL}$. The solution is stirred in a hot water bath for $12 \mathrm{~h}$ at $50^{\circ} \mathrm{C}$ until it turns orange. The solution is then added to a small beaker after it has cooled down and is then washed with $20.0 \mathrm{~mL}$ of double-distilled water, then $16.0 \mathrm{~mL}$ of $\mathrm{HCl}$ is added to it, the product first becomes foam and then changes to white crystals.

The solution is filtrated with a water suction pump, it changes to light yellow precipitation as the final product, which is insoluble in benzene but dissolves in 2propanol. The amount of produced 2,3-dihydro-6-methyl-2thioxopyrimidin-( $1 H$ )-one (I) $18.2 \mathrm{~g}$ in $64 \%$ yield with m.p. $235^{\circ} \mathrm{C}$.

Rate of Flow in TLC (Rf) $=0.27$, Anal. Calcd (\%) for $\mathrm{C}_{5} \mathrm{H}_{6} \mathrm{~N}_{2} \mathrm{OS}, \mathrm{C}, 42.53 ; \mathrm{H}, 4.03 ; \mathrm{N}, 19.54 ; \mathrm{S}, 22.76$, found: (\%) C, 42.24; H, 4.23; N, 19.27; S, 22.54 .

2.2. 2-(2,6-Dihydro-4-methyl-6-oxopyrimidin-2-ylthio)ethanoic Acid (II). A three-necked round-bottomed flask with a thermometer, a back flow condenser along with a magnetic stirrer are prepared for the experiment; 2,3-dihydro-6methyl-2-thioxopyrimidin- $(1 H)$-one (I) $3.55 \mathrm{~g}(0.025 \mathrm{~mL})$, 2-chloroacetic acid $2.4 \mathrm{~g}(0.25 \mathrm{~mL})$ and dimethyl sulfoxide (DMSO) $20.0 \mathrm{~mL}$ as a solvent are added to the flask and heated up to $60-65^{\circ} \mathrm{C}$.

Light yellow-colored crystals, which are insoluble in propanone but soluble in water, are formed if the flask is put in ice. Product (II) is $3.0 \mathrm{~g}$, in $61.50 \%$ yield with m.p. $220^{\circ} \mathrm{C}$. $\mathrm{Rf}=0.49$, Anal. Calcd. (\%) for $\mathrm{C}_{7} \mathrm{H}_{8} \mathrm{~N}_{2} \mathrm{O}_{3} \mathrm{~S}, \mathrm{C}, 41.03 ; \mathrm{H}, 4.04$; N, 14.11; S, 16.01, found: (\%) C, 42.00; H, 4.00; N, 14.00; S, 16.00

2.3. Copper Di(2(-1,6-dihydro-4-methyl-6-oxopyrimidin-2-ylthio)ethanoate (III). A three-necked round-bottomed flask with a thermometer, a back flow condenser along with a magnetic stirrer are prepared for the experiment; 2-(2,6-dihydro4-methyl-6-oxopyrimidin-2-ylthio)ethanoic acid (II) $3.0 \mathrm{~g}$ $(0.02 \mathrm{~mL})$, copper sulphate $3.2 \mathrm{~g}(0.02 \mathrm{~mL})$, and $15.0 \mathrm{~mL}$ distilled water are added to the flask and stirred fast. The reaction continues for $5 \mathrm{~h}$ at $60-70^{\circ} \mathrm{C}$. Then it is cooled down to room temperature. $3.44 \mathrm{~g}$ copper salt (III) in $80 \%$ yield with m.p. $270^{\circ} \mathrm{C}$ is separated from the rest of the solution in the form of precipitated crystals. $\mathrm{Rf}=0.38$ Anal. Calcd. (\%) for $\mathrm{CuC}_{14} \mathrm{H}_{16} \mathrm{~N}_{4} \mathrm{O}_{6} \mathrm{~S}_{2}, \mathrm{C}, 36.47 ; \mathrm{H}, 3.23 ; \mathrm{N}, 12.34 ; \mathrm{S}, 13.52$, found: (\%) C, 36.36; H, 3.03; N, 12.12; S, 13.85 .

2.4. 2-(2-Hydroxyethylthio)-6-methylpyrimidin-4(3H)-one $(I V)$. A three-necked round-bottomed flask with a thermometer, a back flow condenser and a magnetic stirrer are prepared for the experiment. 2,3-Dihydro-6-methyl2-thioxopyrimidin-(1H)-one (I) $4.26 \mathrm{~g} \quad(0.02 \mathrm{~mL})$, 2chloroethanol $1.8 \mathrm{~g}(0.02 \mathrm{~mL})$, DMSO $10 \mathrm{~mL}$ and $\mathrm{K}_{2} \mathrm{CO}_{3}$ $8.28 \mathrm{~g}(0.06 \mathrm{~mL})$ are added to the flask and stirred at room temperature. The solution in the flask alongside ethanol converts to precipitate in four hours. Dark yellow crystals are recrystallized by hexane and then filtered, the product is free from chlorine which is insoluble in DMSO, ethanol, buthanol and benzene, but soluble in water. The product (IV) in $69 \%$ yield and has m.p. $210^{\circ} \mathrm{C} . \mathrm{Rf}=0.58$, Anal. Calcd. 
TABLE 1: The physicochemical characteristics of synthesized derivatives of 2,3-dihydro-6-methyl-2-thioxopyrimidin-(1H)-one, (I-IX).

\begin{tabular}{|c|c|c|c|c|c|c|c|}
\hline \multirow{3}{*}{ Products } & \multirow{3}{*}{ Yields \% } & \multirow{3}{*}{ Temp mp, ${ }^{\circ} \mathrm{C}$} & \multicolumn{5}{|c|}{ Elemental analysis } \\
\hline & & & \multirow{2}{*}{ Mol. formula } & \multicolumn{4}{|c|}{ Calculated/found, \% } \\
\hline & & & & $\mathrm{C}$ & $\mathrm{H}$ & $\mathrm{N}$ & S \\
\hline \multirow{2}{*}{ I } & \multirow{2}{*}{64} & \multirow{2}{*}{235} & \multirow{2}{*}{$\mathrm{C}_{5} \mathrm{H}_{6} \mathrm{~N}_{2} \mathrm{OS}$} & 42.53 & 4.03 & 19.54 & 22.76 \\
\hline & & & & 42.25 & 4.23 & 19.72 & 22.54 \\
\hline \multirow{2}{*}{ II } & \multirow{2}{*}{61.5} & \multirow{2}{*}{220} & \multirow{2}{*}{$\mathrm{C}_{7} \mathrm{H}_{8} \mathrm{~N}_{2} \mathrm{O}_{3} \mathrm{~S}$} & 41.03 & 4.04 & 14.11 & 16.01 \\
\hline & & & & 42 & 4 & 14 & 16 \\
\hline \multirow{2}{*}{ III } & \multirow{2}{*}{80} & \multirow{2}{*}{270} & \multirow{2}{*}{$\mathrm{C}_{14} \mathrm{H}_{16} \mathrm{~N}_{4} \mathrm{O}_{6} \mathrm{~S}_{2} \mathrm{Cu}$} & 36.47 & 3.23 & 12.34 & 13.52 \\
\hline & & & & 36.36 & 3.03 & 12.12 & 13.85 \\
\hline \multirow{2}{*}{ IV } & \multirow{2}{*}{69} & \multirow{2}{*}{210} & \multirow{2}{*}{$\mathrm{C}_{7} \mathrm{H}_{10} \mathrm{~N}_{2} \mathrm{O}_{2} \mathrm{~S}$} & 45.02 & 5.54 & 15.28 & 16.89 \\
\hline & & & & 45.16 & 5.38 & 15.05 & 17.20 \\
\hline \multirow{2}{*}{ V } & \multirow{2}{*}{44} & \multirow{2}{*}{200} & \multirow{2}{*}{$\mathrm{C}_{8} \mathrm{H}_{11} \mathrm{~N}_{2} \mathrm{O}_{2} \mathrm{SCl}$} & 40.72 & 4.81 & 11.75 & 13.84 \\
\hline & & & & 40.94 & 4.69 & 11.94 & 13.65 \\
\hline \multirow{2}{*}{ VI } & \multirow{2}{*}{100} & \multirow{2}{*}{340} & \multirow{2}{*}{$\mathrm{C}_{5} \mathrm{H}_{5} \mathrm{~N}_{2} \mathrm{OSNa}$} & 36.28 & 3.23 & 17.29 & 19.28 \\
\hline & & & & 36.59 & 3.05 & 17.07 & 19.51 \\
\hline \multirow{2}{*}{ VII } & \multirow{2}{*}{67} & \multirow{2}{*}{210} & \multirow{2}{*}{$\mathrm{C}_{8} \mathrm{H}_{10} \mathrm{~N}_{2} \mathrm{O}_{2} \mathrm{~S}$} & 48.22 & 5.16 & 14.35 & 16.47 \\
\hline & & & & 48.48 & 4.05 & 14.14 & 16.16 \\
\hline \multirow{2}{*}{ VIII } & 635 & 240 & $\mathrm{C}_{1}$ & 45.36 & 4.63 & 15.03 & 17.55 \\
\hline & 05.0 & 240 & $\mathrm{C}_{7} \mathrm{H}_{8} \mathrm{~N}_{2} \mathrm{U}_{2} \mathrm{~S}$ & 45.65 & 4.35 & 15.22 & 17.39 \\
\hline IX & 573 & 215 & & 58.72 & 4.18 & 11.4 & 13.25 \\
\hline $1 \Lambda$ & & 210 & $\mathrm{C}^{1}$ & 58.54 & 4.07 & 11.38 & 13.01 \\
\hline
\end{tabular}<smiles>CCOC(=O)CC(C)=O</smiles>

FIGURE 1: Syntheses of 2,3-dihydro-6-methyl-2-thioxopyrimidin$(1 H)$-one (I).

(\%) for $\mathrm{C}_{7} \mathrm{H}_{10} \mathrm{~N}_{2} \mathrm{O}_{2} \mathrm{~S}, \mathrm{C}, 45.02 ; \mathrm{H}, 5.54 ; \mathrm{N}, 15.28 ; \mathrm{S}, 16.89$, found: (\%) C, 45.16; H, 5.38; N, 15.05; S, 17.20 .

2.5. 2-(3-Chloro-2-hydroxypropylthio)-6-methylpyrimidin-4 $(3 \mathrm{H})$-one $(\mathrm{V})$. A three-necked round-bottomed flask with a thermometer, a back flow condenser and a magnetic stirrer are prepared for the experiment. 2,3-Dihydro-6-methyl-2thioxopyrimidin-( $1 \mathrm{H})$-one (I) $3.33 \mathrm{~g}(0.02 \mathrm{~mL}), \mathrm{Na}_{2} \mathrm{CO}_{3}$ $2.0 \mathrm{~g}(0.02 \mathrm{~mL})$ and ethanol $(20.0 \mathrm{~mL})$ are added to the flask and stirred fast. 2-(Chloromethyl)oxirane is added to the flask drop wise and is stirred at room temperature for $5 \mathrm{~h}$. The mixture of the reaction is extracted by ester and it has separated in the form of white precipitates by a water suction pump. Crystals are $200^{\circ} \mathrm{C}$. Rf $=0.48$, Anal. Calcd. (\%) for $\mathrm{C}_{6} \mathrm{H}_{11} \mathrm{~N}_{2} \mathrm{O}_{2} \mathrm{SCl}, \mathrm{C}, 40.72 ; \mathrm{H}, 4.81 ; \mathrm{N}, 11.75 ; \mathrm{S}, 13.48$, found: (\%) C, 40.94; H, 4.69; N, 11.94; S, 13.65.

2.6. Sodium Salt of 2,3-Dihydro-6-methyl-2-thioxopyrimidin(1H)-one (VI). A mixture of 2,3-dihydro-6-methyl-2-thioxopyrimidin-( $1 \mathrm{H})$-one (I) $1.5 \mathrm{~g}(0.01 \mathrm{~mL}), \mathrm{NaOH} 0.40 \mathrm{~g}$ and<smiles>Cc1cc(=O)[nH]c(SCC(=O)O)n1</smiles>

FIGURE 2: Syntheses of 2-(2,6-dihydro-4-methyl-6-oxopyrimidin-2ylthio)ethanoic acid (II).

$\mathrm{H}_{2} \mathrm{O} 7.0 \mathrm{~mL}$ was added to a small beaker and mixed together. After 4-5 h of stirring precipitation in the form of crystals appear on the magnetic stirrer. Crystals are filtered, separated and are recrystallized by ethanol. The white crystals are in $100 \%$ yield with m.p. $340^{\circ} \mathrm{C} . \mathrm{Rf}=0.59$, Anal. Calcd. (\%) for $\mathrm{NaC}_{5} \mathrm{H}_{5} \mathrm{~N}_{2} \mathrm{OS}, \mathrm{C}, 36.28 ; \mathrm{H}, 3.23 ; \mathrm{N}, 17.29 ; \mathrm{S}, 19.28$, found: (\%) C, 36.59; H, 3.05; N, 17.07; S, 19.51.

2.7. 2-((Oxiran-2-yl)methylthio)-6-methylpyrimidin-4(3H)one (VII). A three-necked round-bottomed flask, a back flow condenser, a thermometer and a magnetic stirrer are prepared. Sodium salt of 2,3-dihydro-6-methyl-2thioxopyrimidin-( $1 \mathrm{H})$-one (VI) $3.3 \mathrm{~g}(0.02 \mathrm{~mL})$ and $\mathrm{NaOH}$ $0.8 \mathrm{~g}(0.02 \mathrm{~mL})$ are dissolved in $15.0 \mathrm{~mL}$ of distilled water and are added to the flask and then stirred fast. Initially there is no change, but after $10 \mathrm{~h}$, white precipitate is formed. This precipitation is insoluble in water, but it dissolves in 2-propanol by heating and it precipitates after cooling down again. 
<smiles>C=C1C=C(C)N=C(SCC(=O)OCC(C)C(=O)OCC(=O)O)N1</smiles>

FIGURE 3: Syntheses of copper di(2(-1,6-dihydro-4-methyl-6oxopyrimidin-2-yl-thio)ethanoate (III).<smiles>Cc1cc(=O)[nH]c(SCCO)n1</smiles>

FIGURE 4: Syntheses of 2-(2-hydroxyethylthio)-6-methylpyrimidin$4(3 H)$-one (IV).

It can be recrystallized by 2-propanol after filtration, the final product as a crystals (VII) $2.7 \mathrm{~g}$ in $67 \%$ yield with m.p. $210^{\circ} \mathrm{C}$ is collected. $\mathrm{Rf}=0.59$, Anal. Calcd (\%) for $\mathrm{C}_{8} \mathrm{H}_{10} \mathrm{~N}_{2} \mathrm{O}_{2} \mathrm{~S}, \mathrm{C}, 48.22 ; \mathrm{H}, 5.16 ; \mathrm{N}, 14.35 ; \mathrm{S}, 16.47$, found: (\%) C, 48.48; H, 5.05; N, 14.14; S, 16.16 .

2.8. S-1,6-Dihydro-4-methyl-6-oxopyrimidin-2-yl-ethanethioate (VIII). For this reaction 2,3-dihydro-6-methyl-2-thioxopyrimidin- $(1 H)$-one (I) $1.24 \mathrm{~g}(0.01 \mathrm{~mL})$, acetyl chloride $0.8 \mathrm{~g}(0.01 \mathrm{~mL})$ and benzene $5.0 \mathrm{~mL}$ as a solvent are added to a small beaker and stirred for $8 \mathrm{~h}$ by a magnetic stirrer. The produced compound is insoluble in water, ethanol, and $\mathrm{CCl}_{4}$ even by heating, but it dissolves well in DMSO.

The produced precipitation (VIII) $1.2 \mathrm{~g}$ in $63.5 \%$ yield with m.p. $240^{\circ} \mathrm{C}$ recovered. $\mathrm{Rf}=0.782$, Anal. Calcd. (\%) for $\mathrm{C}_{7} \mathrm{H}_{8} \mathrm{~N}_{2} \mathrm{O}_{2} \mathrm{~S}, \mathrm{C}, 45.36 ; \mathrm{H}, 4.63 ; \mathrm{N}, 15.03 ; \mathrm{S}, 17.55$, found: (\%) C, 45.65; H, 4.34; N, 15.22; S, 17.30.

2.9. S-1,6-Dihydro-4-methyl-6-oxopyrimidin-2-yl-benzothioate (IX). A mixture of 2,3-dihydro-6-methyl-2-thioxopyrimidin- $(1 H)$-one (I) $1.4 \mathrm{~g}(0.01 \mathrm{~mL})$, benzoyl chloride $1.4 \mathrm{~g}(0.01 \mathrm{~mL})$ and benzene $5.0 \mathrm{~mL}$ was stirred for $5 \mathrm{~h}$ at room temperature. The collected precipitation is washed with EtOH and then filtered. The product (IX) is insoluble in propanone and benzene. It is $1.3 \mathrm{~g}$ in $57 \%$ yield with m.p. $215^{\circ}$ C. Anal. Calcd. (\%) for $\mathrm{C}_{12} \mathrm{H}_{10} \mathrm{~N}_{2} \mathrm{O}_{2} \mathrm{~S}, \mathrm{C}, 58.72 ; \mathrm{H}, 4.18$; $\mathrm{N}, 11.14 ; \mathrm{S}, 13.25$, found: (\%) C, 58.54; H, 4.07; N, 11.38; S, 13.01 .

\section{Results and Discussion}

As a result of the condensation of ethyl-3-oxobutanoate with thiourea in a $\mathrm{KOH}$ and ethanol medium, in a hot water bath while evaporation of ethanol is in progress, the rest compound dissolved in water. Afterwards, the neutralization<smiles>CCc1cc(=O)[nH]c(SCC(O)CCl)n1</smiles>

FIGURE 5: Syntheses of 2-(3-chloro-2-hydroxypropylthio)-6-methylpyrimidin-4(3H)-one (V).<smiles>Cc1cc(=O)[nH]c(SN=O)n1</smiles>

Figure 6: Syntheses of sodium salt of 2,3-dihydro-6-methyl-2thioxopyrimidin-(1H)-one (VI).

is done by $\mathrm{HCl}$ or $\mathrm{CH}_{3} \mathrm{COOH} 10 \%$. The result of the reaction is as follow and it produces 2,3-dihydro-6-methyl2-thioxopyrimidin-( $1 H$ )-one (I), (Figure 1). 2,3-Dihydro6-methyl-2-thioxopyrimidin- $(1 H)$-one (I) reacts with 2chloroacetic acid in alkaline $\mathrm{KOH}$ solution at room temperature after $20 \mathrm{~h}$. Then it is acidified by acetic acid and produces the derivative of carboxylate (II), (Figure 2). The resulting derivative of carboxylate (II) produced a new copper salt (III) in the reaction with the salt of copper sulphate (Figure 3 ). According to the following reaction, 2,3-dihydro-6-methyl2-thioxopyrimidin- $(1 H)$-one (I) in $\mathrm{KOH}$ aqueous solution reacts with 2 -chloroethanol after $6-8 \mathrm{~h}$ in a hot water bath and produces compound (IV), (Figure 4). In the next step, the reaction of 2,3-dihydro-6-methyl-2-thioxopyrimidin(1H)-one with 2-(chloromethyl)oxirane in the presence of $\mathrm{KOH}$ aqueous solution the product will be 2-(3-chloro-2hydroxypropylthio)-6-methylpyrimidin-4(3H)-one (V) and the reaction is as follows (Figure 5). According to obtained reactions, if 2,3-dihydro-6-methyl-2-thioxopyrimidin- $(1 H)$ one (I) reacts with $\mathrm{NaOH}$ compound (VI) is produced, (Figure 6) and then (VI) reacts with 2-(chloromethyl)oxirane and results in a substituted derivative of oxiranyl (VII), (Figure 7).

Different acylation reagents (acetyl chloride, benzoyl chloride) in reaction with 2,3-dihydro-6-methyl-2-thioxopyrimidin- $(1 H)$-one $(\mathrm{I})$, in $\mathrm{DMF}$ at $20^{\circ} \mathrm{C}$ were studied. In this reaction acylation happens on sulfur and produces $\mathrm{S}$-acylified derivatives (VIII-IX), (Figure 8).

In the IR spectrum, the absorption band characteristics of the synthesized derivatives of 2,3-dihydro-6-methyl-2thioxopyrimidin-( $1 H)$-one (I-IX), appear in the range of $1630-1720 \mathrm{~cm}^{-1}$. This range belongs to the bands of pyrimidine fragments $[\mathrm{C}=\mathrm{O},=\mathrm{N}-\mathrm{C}=\mathrm{O}]$.

In this spectroscopy $\mathrm{N}-\mathrm{H}$ stretching will be at 3300$3400 \mathrm{~cm}^{-1}$; furthermore absorption bands at the region of 
<smiles>Cc1cc(=O)[nH]c(SCC2CO2)n1</smiles>

FIGURE 7: Syntheses of 2-((oxiran-2-yl)methylthio)-6-methylpyrimidin-4(3H)-one (VII).

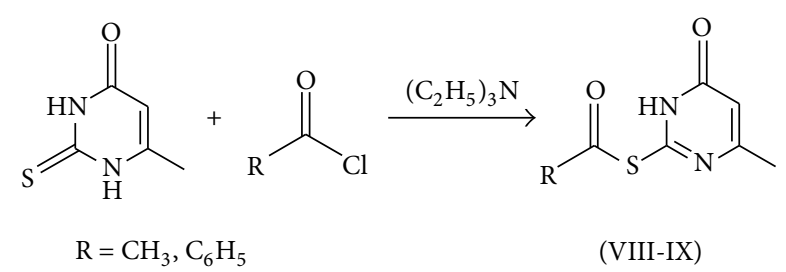

FIGURE 8: Syntheses of S-1,6-dihydro-4-methyl-6-oxopyrimidin2-yl-ethanethioate (VIII) and S-1.6-dihydro-4-methyl-6oxopyrimidin-2-yl-benzothioate (IX).

$3090-3100 \mathrm{~cm}^{-1}$ characterize the interior hydrogen of $v \mathrm{NH}$. The intensity of the band at $1715 \mathrm{~cm}^{-1}$ reveals the existence of $v(\mathrm{C}=\mathrm{O})$ functional group which itself is evidence of the presence of a carboxyl group in the 2,3-dihydro-6-methyl-2thioxopyrimidin- $(1 H)$-one molecule.

Acetyl and benzoyl groups in (VIII-IX) molecules do not cause any differences in the spectrums of IR. It is more probable that stretching $v \mathrm{C}=\mathrm{O}$ functional group in the region of $1620 \mathrm{~cm}^{-1}$ characterizes the band of $\nu \mathrm{C}=\mathrm{O}$ group of pyrimidine. Some compounds have different molecular structures; and their IR spectrums appear in $1170-1180 \mathrm{~cm}^{-1}$ region.

In the spectroscopy of ${ }^{1} \mathrm{H}$ NMR of 2,3-dihydro-6-methyl2-thioxopyrimidin- $(1 H)$-one, the signals of the three protons of the methyl group at a high field $2.1 \mathrm{MHz}$ are observed as a singlet. The single protons of the methine $(\mathrm{CH})$ group in $6.7 \mathrm{MHz}$ and that of amino $(\mathrm{NH})$ group in $12.3 \mathrm{MHz}$ appeared as singlet.

The molecular structure of 2,3-dihydro-6-methyl-2thioxopyrimidin- $(1 H)$-one in ${ }^{13} \mathrm{C}$ NMR spectrum has also been proved. The carbon of the methyl group appeared in a strong field of $19 \mathrm{MHz}$ and the splitting carbon of hydrogen double bond group appeared at the $104 \mathrm{MHz}$ field.

Signals of carbon atoms existing in uracil groups in ${ }^{13} \mathrm{C}$ NMR spectrum appeared at 153 and $162 \mathrm{MHz}$ fields and the signals of the carbon atom of thion- $(\mathrm{C}=\mathrm{S})$ group appears at a downfield of $178 \mathrm{MHz}$. In all of the synthesized and obtained compounds, signals of carbon atoms' in ${ }^{13} \mathrm{C}$ NMR spectra of pyrimidin-4(3H)-one molecule were $164(\mathrm{C} 4), 157$ (C2), 153 (C6), and 98-102 MHz (C5). The physical-chemical constants and yields of synthesized derivatives of 2,3-dihydro6-methyl-2-thioxopyrimidin-(1H)-one (I-IX) are given in Table 1.

\section{Conclusion}

In this paper we have presented methods for the synthesis and cyclization reactions based on a strategy to access and produce the heterocyclic compounds. In this state some of their remarkable reactions were also demonstrated.

The first synthesis is based on the reaction of ethyl cyanoacetate and thiocarbamide in the presence of sodium acetate, and produced 2,3-dihydro-6-methyl-2thioxopyrimidin-4(1H)-one (I).

The cyclized product (I), in different reaction conditions afforded different types of products (II-IX). The synthesized products were confirmed by IR, ${ }^{1} \mathrm{H}{ }^{13} \mathrm{C}$ NMR, and element analysis.

\section{References}

[1] Ch. T. Jurgenson, T. P. Begley, and S. E. Ealick, “The structural and biochemical foundations of thiamin biosynthesis," Annual Review of Biochemistry, vol. 78, pp. 569-603, 2009.

[2] E. Cb. Taylor, The Chemistry of Heterocyclic Compounds, Interscience, New York, NY, USA, 1985.

[3] T. J. Lomis, J. F. Suida, and R. E. Shepherd, "Bleomycin metal site models with apical imidazole or sulphydryl donors," Journal of the Chemical Society, Chemical Communications, no. 4, pp. 290-292, 1988.

[4] I. Yildirim, I. Koca, M. Dincer, and N. O. Andac, "Crystal and molecular structure of 1-allyl-5-(4-methylbenzoyl)-4-(4methylphenyl)pyrimidine-2(1H)-thione," Crystal Research and Technology, vol. 41, no. 12, pp. 1236-1241, 2006.

[5] E. De Clercq and R. T. Walker, Eds., Targets for the Design of Antiviral Agents, Plenum, New York, NY, USA, 1984.

[6] A. Camito, M. Perrissin, and C. Luu-Due, "Synthesis and pharmacological activities of some 3-substituted thienopyrimidin4-one-2-thiones," European Journal of Medicinal Chemistry, vol. 25 , no. 8, pp. 635-639, 1990.

[7] E. S. Badawey and and A. M. El-Ashanawey, "Nonsteroidal antiinflammatory agents-part 1: antiinflammatory, analgesic and antipyretic activity of some new 1-(pyrimidin2-yl)-3-pyrazolin-5-ones and 2-(pyrimidin-2-yl)-1,2,4,5,6,7hexahydro-3H-indazol-3-ones," European Journal of Medicinal Chemistry, vol. 33, no. 5, pp. 349-361, 1998.

[8] S. Vega, J. Aonso, J. A. Diaz, and F. Junquera, "Synthesis of 3substituted-4-phenyl-2-thioxo-1,2,3,4,5,6,7,8-octahydrobenzo [4,5]thieno[2,3-á]pyrimidines," Journal of Heterocyclic Chemistry, vol. 27, no. 2, pp. 269-273, 1990.

[9] J. Satow, Y. Kondo, Y. Kudo et al., "Pyrimidine derivatives, herbicides and plant growth regulators," Patent 5773388, Assignee: Nissan Chemical Industries, June 1998, US Patent Application: 08/592,298.

[10] P. J. Bhuyan, H. N. Borah, and J. S. Sandhu, "Studies on uracils: an efficient method for the synthesis of novel 1-allyl-6$\left(1^{\prime}, 2^{\prime}, 3^{\prime}\right.$-triazolyl) analogues of KEPT,' Journal of the Chemical Society-Perkin Transactions 1, no. 21, pp. 3083-3084, 1999.

[11] R. Pantikis and C. Monneret, "Synthesis of deoxy analogs of HEPT involving a palladium (0) catalyzed coupling," Tetrahedron Letters, vol. 34, no. 25, pp. 4351-4354, 1994.

[12] E. Y. Sutcliffe, K. Y. Zee-Cheng, C. C. Cheng, and R. K. Robins, "Potential purine antagonists. XXXII. The synthesis 
and antitumor activity of certain compounds related to 4aminopyrazolo [3,4-d] pyrimidine," Journal of Medicinal and Pharmaceutical Chemistry, vol. 5, no. 3, pp. 588-607, 1962.

[13] V. I. Ivanskiy, Chemistry of Heterocyclic Compounds, Visshaya Shkola, Moscow, Russia, 1978.

[14] A. T. Soldateukov, N. M. kolyadina, and I. V. Shendrik, Eds., Fundamentals of Chemistry, Organic drugs, Moscow, Russia, 2003.

[15] V. P. Krivonogov, G. A. Tolstikov, and U. I. Murinor, Pharmaceutical Chemistry Journal, vol. 31, article 24, 1997.

[16] S. H. Youssif, B. Bayoumy, B. Bayoumy, and S. ElBahaie, "A novel synthesis of 3,9-dialkyl and 8-Aryl-3,9dimethylxanthines," Bulletin of the Korean Chemical Society, vol. 23, no. 3, pp. 374-380, 2003.

[17] M. Barmaki, A. M. Maharramov, and M. A. Allahverdiyev, Eds., Kimya Problemlari, Baku State University Press, Baku, Azerbaijan, 2007.

[18] M. Barmaki, A. M. Maharramov, and M. A. Allahverdiyev, "Synthesis of uracil derivatives and some of their reactions," Asian Journal of Chemistry, vol. 20, no. 7, pp. 5277-5281, 2008.

[19] A. Gondela and K. Walczak, "New approach for the synthesis of 1-aryl- and 1-heteroaryl-5-nitrouracil derivatives," Tetrahedron, vol. 63, no. 13, pp. 2859-2864, 2007.

[20] R. Chioua, F. Benabdelouahab, M. Chioua, R. MartínezAlvarez, and A. Herrera Fernández, "Synthesis of novel quinazoline derivatives via pyrimidine ortho-quinodimethane," Molecules, vol. 7, no. 7, pp. 507-510, 2002.

[21] D. Prajapati and M. Gohain, "An efficient synthesis of novel pyrano[2,3-d]- and furopyrano[2,3-d]pyrimidines via indiumcatalyzed multi-component domino reaction," Beilstein Journal of Organic Chemistry, vol. 2, no. 11, pp. 11-14, 2006. 

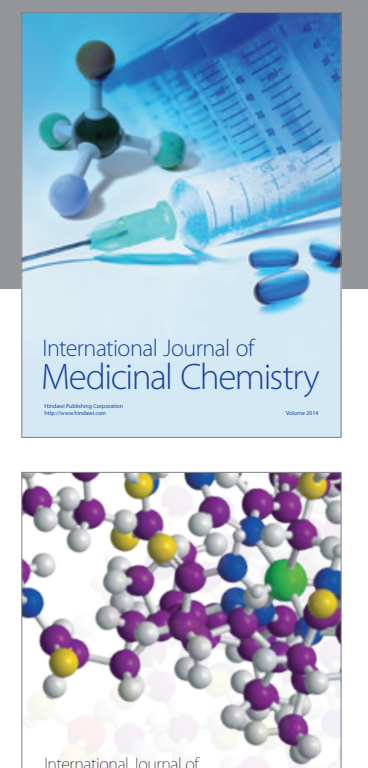

\section{Carbohydrate} Chemistry

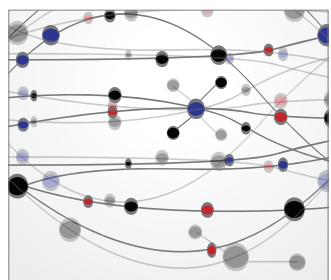

The Scientific World Journal
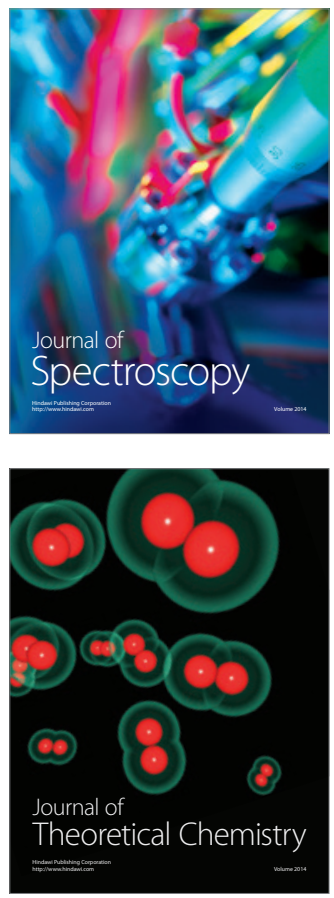
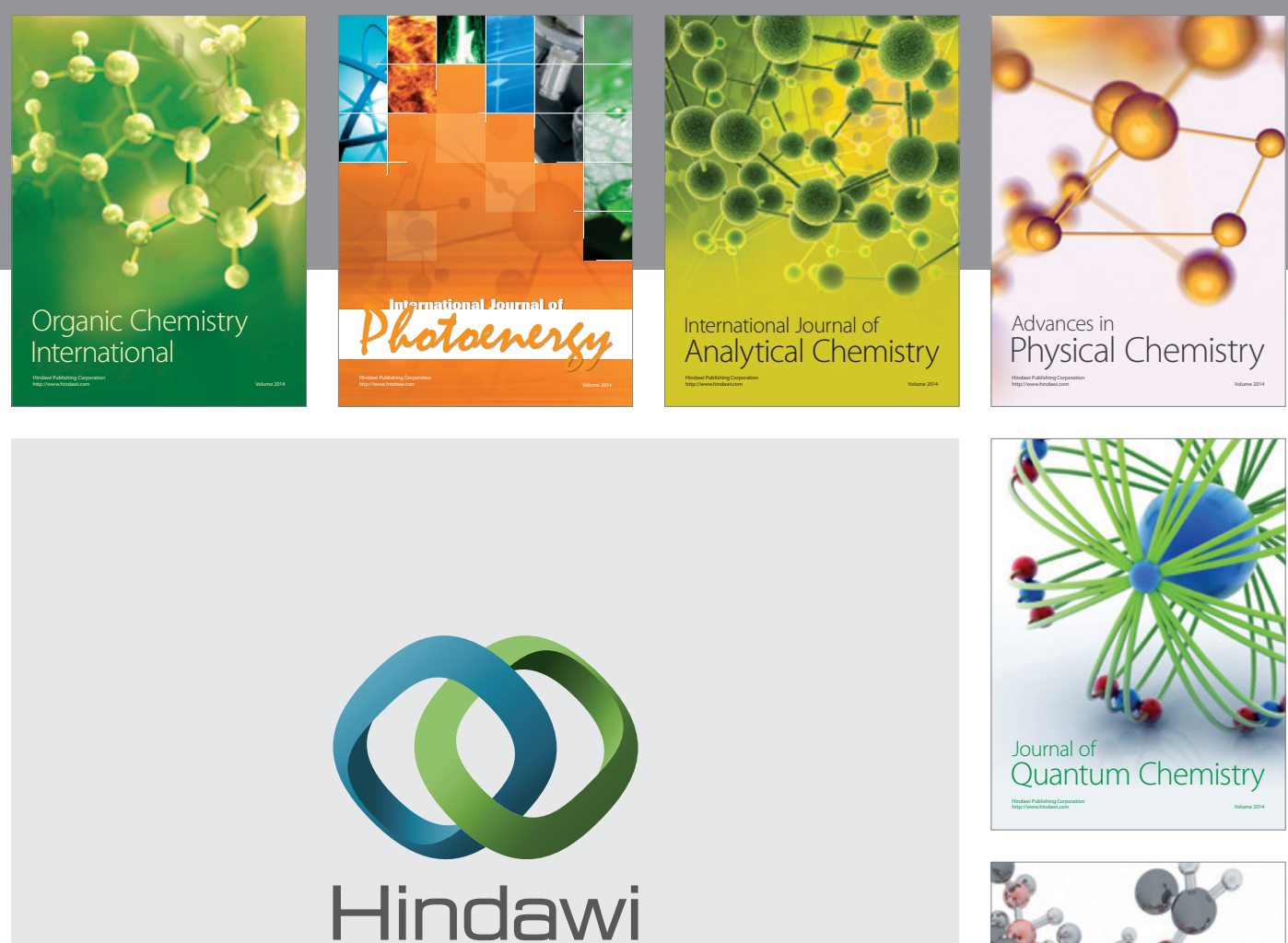

Submit your manuscripts at

http://www.hindawi.com

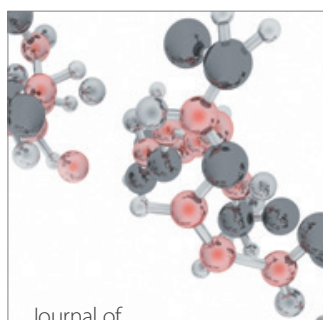

Analytical Methods

in Chemistry

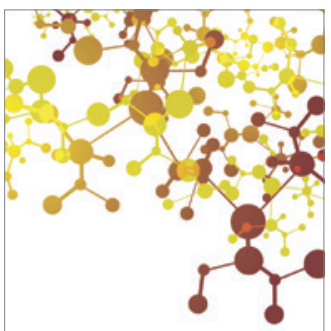

Journal of

Applied Chemistry

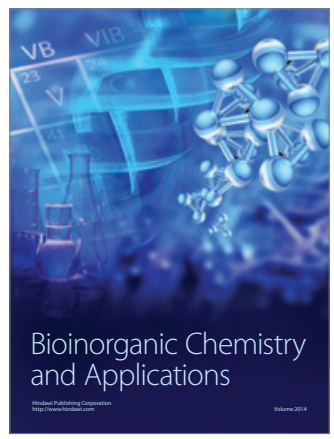

Inorganic Chemistry
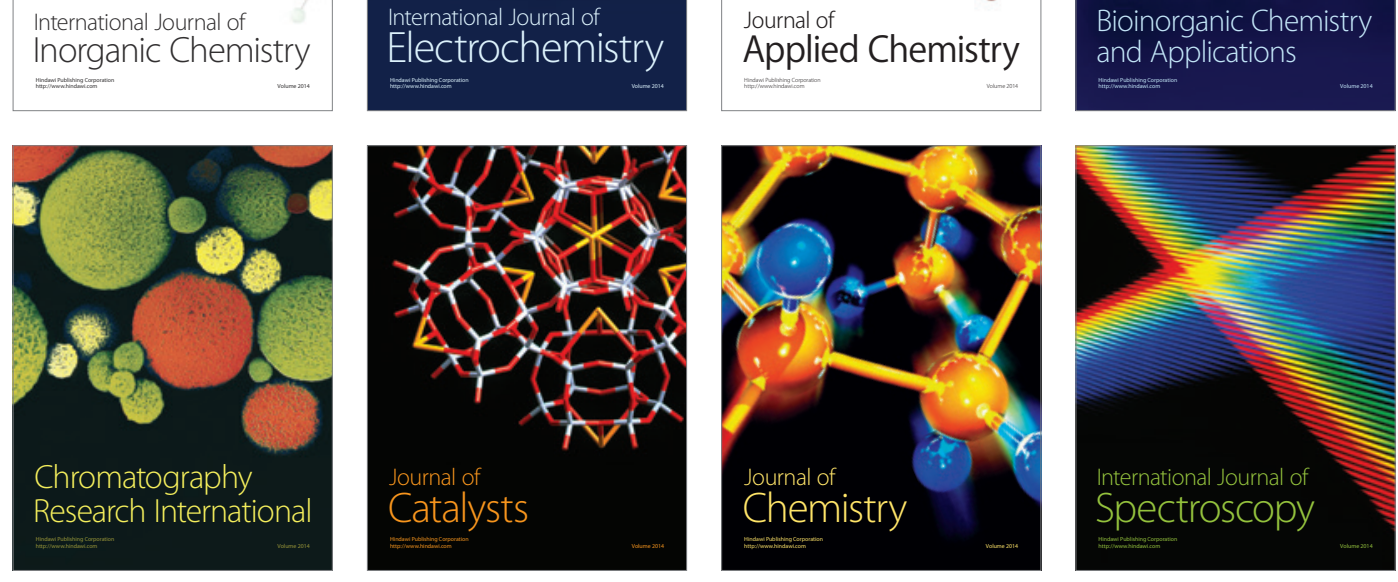